\title{
Green Design in the View of Sustainable Development
}

\author{
Yan $\mathrm{Li}^{1 *}$, Zhenqing Sun ${ }^{1}$ \\ ${ }^{1}$ College of Economics and Management, Tianjin University of Science \& Technology, Tianjin, 300222, China
}

\begin{abstract}
With the continuous rising of economic benefits and the increasing innovation of science and technology, the relationship between human beings and natural environment is becoming more and more prominent. Especially after the world enters into industrialization, human beings plunder resources recklessly and destroy the stable cycle of ecological environment. In recent years, China has put forward the development concept of "not only the golden and silver mountains, but also the lucid waters and lush mountains are invaluable assets". The 13th Five-Year Plan of China has established five development concepts: innovation, coordination, green, openness and sharing. The concept of "green" has been incorporated into the national strategic design, which highlights the harmonious development between human beings and nature, people and people. As the guider in the future, under the background of sustainable development, the green design takes innovation as the starting point, so as to become the permanent motive force of green development.
\end{abstract}

\section{Introduction}

In the report of the 19th National People's Congress of the Communist Party in China, it is clearly pointed out that human beings and nature are the life community, so human beings must respect nature, conform to nature and protect nature[1]. With the rapid development process of human civilization, the relationship between human beings and natural environment is becoming increasingly sharp and contradictory. Especially after the industrial revolution, while enjoying the modern way of life brought about by it, human beings squander the natural resources recklessly, thus leading to the excessive consumption of energy and resources, so that destroying the stability and coordination of ecological environment. Pushing to the modern times, the contradiction between human beings and natural environment has become more and more serious. In the course of exploring the road of sustainable development among human beings, in line with the requirements of era development, the green design emerged as the times require, which has established a solid theoretical foundation and innovative practical approach for further improving the relationship between human beings and natural environment.

\section{Environment and sustainable development}

Green design is put forward based on the background of ecological environment problems, relying on the theory of sustainable development, and in the field of economic and social great mapping, for the sustainable development theory in the human production activities on the ecological resources sustainable use, to the steady development of the green economy, to gradually improve, to green living environment of green rebuilding, provides an important theoretical support.

\subsection{Environmental issues}

The essence of environmental problems is the unreasonable utilization of ecological resources, which mainly refers to various phenomena in the global environment or regions that are not conducive to the survival and development of human society. The root cause is that in the process of using and transforming nature for social production activities, human beings cause changes in the organizational structure of the environment, destroy the stability of ecological balance, and make the normal material environment system unable to be remolded in a normal cycle, resulting in environmental problems.

\subsection{Sustainable development research}

The concept of sustainable development was firstly put forward in the World Conservation Strategy, which was formulated by the International Union for Conservation of Nature in 1980. During the 1960s and 1970s, after the American oceanographer Rachel Carson studied the danger caused by using pesticide, she published a number of books, such as the Silent Spring and so on, which marked the beginning of modern sustainable development idea[3]. Lynn White revealed that the root of environmental crisis comes from the root of Western culture, that is, the "Genesis" itself[4]; in addition, Donella Meadows calculated the limits of resources existing on the earth, so that give us a warning about the

\footnotetext{
*Corresponding author's e-mail: 1198221091@qq.com
} 
crisis of human existence [5]. In 1992, "the 21st Century Agenda" was passed in the United Nations Conference on Environment and Development, which was held in Rio de Janeiro[6]. In recent years, China has clearly and firmly proposed to strengthen the "construction of ecological civilization", which is a national strategic arrangement which combines the current international sustainable development concept with the national conditions in China, and it is also a further deepening to the concept of sustainable development.

\section{Green design theory}

Throughout the world, the research on green design started in the 1970s and 1980s. By summarizing and drawing lessons from the early research results and experience of western developed countries, Chinese design values have gone through three historical stages: "material-oriented", "people-oriented" and "nature-oriented". The study of green design did not reach its full depth until the turn of the century. As the world's largest energy consumer and carbon emitter, China must go through a long process to truly realize green design.

\subsection{Overview of the green design research}

Under the trend of human self-interest, design has changed from a kind of activity planning and intelligent activity for purposeful practice to a behavior mode that promotes human's "mass production, excessive consumption and massive abandonment". With the passage of time and driven by economic benefits, design has become a powerful catalyst for the outbreak of energy crisis. With the development of modern industrial civilization, people's living standards have been constantly improved. In the face of ecological crisis, human society has been deeply reflecting on it. The concept of sustainable development has been put forward.

\subsection{Development of the green Design}

Green design is a new design idea in the era of sustainable development, which focuses on the efficient utilization of resources and energy, gives consideration to both economic and environmental benefits and closely links them. Among the controversies happened in the 1960s and 1970s, Ian McHarg began from the ecology to study the relationship between human beings, nature and environment from a macro perspective in his book named Design With Nature[7]; The "Green Design" was really proposed in the book named Green Design, which was written by Avril Fox and Robin Murrell in 1989. in this book, they advocate the use of renewable building materials, so as to avoid waste of resources[8];In 1994, Leslie Starr Hart put forward "understanding the significance of natural environment profoundly, showing the correct awareness about environmental protection" in The Guiding Principles of Sustainable Design[9]; After entering the 21st century, Lou Yongqi, Qin, Zhu Xiaocun redefined the environmental design in the book named Environmental Design, and put forward the dependent relationship between social factors and environmental design.

\section{Evaluation method of green degree}

Green degree evaluation method is a method of green design evaluation. It is a systematic analysis method that combines quantitative analysis with qualitative analysis and reflects and expresses people's subjective judgment in the form of quantitative indicators. On the basis of AHP, questionnaire survey, weighted average and regression analysis were combined.

\subsection{Evaluation index system}

Through the comprehensive analysis of the technical index, economic index and ecological index of the product, a perfect index system and scientific evaluation method are established to evaluate the green degree of the product. There are both qualitative and quantitative indicators in the index system, which can transform subjective qualitative evaluation into objective quantitative evaluation and form a complex system of evaluation. The product green evaluation index system is shown in table 1 below.

Table 1. Green product evaluation index system

\begin{tabular}{|c|c|c|c|}
\hline Level 1 index & Level 2 index & Level 3 index & Level 4 index \\
\hline \multirow{11}{*}{$\begin{array}{l}\text { Green product } \\
\text { evaluation index } \\
\text { system }\end{array}$} & Technical & Functional & Main function, Auxiliary function \\
\hline & indicators & Technical manufacturability & Safety, Packaging,Transportation \\
\hline & \multirow{5}{*}{$\begin{array}{l}\text { Economic } \\
\text { indicators }\end{array}$} & & Raw material cost,Development \\
\hline & & Preservice cost & cost,Manufacturing cost \\
\hline & & In-service cost & Maintenance cost, Operation cost, \\
\hline & & In-service cost & Publicity cost \\
\hline & & After-use cost & $\begin{array}{c}\text { Recovery cost, Repair cost, Pollution } \\
\text { disposal cost }\end{array}$ \\
\hline & \multirow{4}{*}{$\begin{array}{l}\text { Ecological } \\
\text { indicators }\end{array}$} & Energy consumption & Types of energy,Energy efficiency \\
\hline & & Air pollution & Greenhouse gases, dust,soot \\
\hline & & Water pollution & Biological parameter index \\
\hline & & Soil pollution & Harmful heavy metal index \\
\hline
\end{tabular}




\subsection{Importance index setting}

Using the analytic hierarchy process (AHP), the complex problem is firstly decomposed into several factors according to the index system, and the relative importance degree of each factor is described by comparisons among the factors. The weight of different schemes can be obtained through calculation, as shown in table 2 below.

Table 2. Level of importance program

\begin{tabular}{cc}
\hline Degree of importance & The relationship between the two elements $B_{i}$ and $B_{j}$ \\
\hline 1 & $B_{i}$ is just as important as $B_{j}$ \\
3 & $B_{i}$ is slightly more important than $B_{j}$ \\
5 & $B_{i}$ is obviously more important than $B_{j}$ \\
7 & $B_{i}$ is more important than $B_{j}$ \\
9 & $B_{i}$ is more important than $B_{j}$ \\
reciprocal & If $B_{i} / B_{j}=\mathrm{m}_{\mathrm{i}}$, then $B_{j} / B_{i}=1 / \mathrm{m}_{\mathrm{i}}$ \\
\hline
\end{tabular}

\subsection{Comprehensive evaluation of product greenness}

The comprehensive evaluation of product greenness only needs to sum the index value and weight of each index.

The exponential weighted sum of the sub-indexes $m_{i}$ of any index in the three-level index layer is obtained to obtain the index of the index $D_{i j} \quad(i, j=1,2,3 \ldots n)$; then the weighted sum of all the indexes in the second-order index layer, remember that the index of this criterion

$$
D_{i(\mathrm{i}=1,2,3 \ldots \mathrm{n}) \text {, namely }} D_{i}=\sum_{j=1}^{n} D_{i j} \bullet W_{i j} \text {; Calculate }
$$
the green comprehensive evaluation value of the product

$$
\Omega=\sum_{i=1}^{n} D_{i} \bullet W_{i}
$$
green degree of the product. The higher the value, the higher the greenness of the product.

\section{Conclusion}

Green design is the product of the trend of thought of sustainable development and the centralized projection of sustainable development in the field of economy and society. Green design under the sustainable development can not only deal with the relationship between natural environment and pre-production, but also coordinate the relationship between natural environment, social environment and pre-production, which can meet the development needs of contemporary people and the sustainable development of generations in the future. The road to green development in China depends on the leading of green design, from "only golden and silver mountains, regardless of lucid waters and lush mountains" to "not only the golden and silver mountains, but also the lucid waters and lush mountains are invaluable assets" to "lucid waters and lush mountains equal to the golden and silver mountains", in the construction of environment-friendly and resource-conserving society, green design has become the "first tier" of green development and the "first wealth" of green development.

\section{Acknowledgments}

The author would like to thank colleagues for their help or encouragement, technical staff for their work, and the organizing committee and organizers of the 4th international conference on renewable energy and environmental protection for their platform and academic exchange opportunities.

\section{Reference}

1. Information on http://www.xinhuanet.com/

2. Andrews D.The circular economy,design thinking and education for sustainability Science.Local economy. 17(2015)124-137.

3. Wenzel, et al.Environmental Assessment of Product, Vol.1.London: Chapman\&Hall, 1997.

4. Russell E Dicarlo.Towards a New World View.Pennsylvania: Epic Publishing, 1996.

5. Yan Li.Study on the Green Design Concept in the Low Carbon Era.Packaging Engineering.36 (2015)108-111.

6. Alting L.Life cycle engineering and design.CIRP Annals Manufacturing Technology.44 (1995)569-580.

7. Chowdhury M M H, Quaddus M A.A multi-phased QFD based optimization approach to sustainable service design.International Journal of Production Economics. 171(2016) 165-178. 
8. Tesheng L, Hsinghsin H.Applying TRIZ and Fuzzy AHP to develop innovative design for automated manufacturing systems[J].Expert systems with application.36 (2009) 302-312.

9. Fan Z P, Li Y H, Wang X, et al.Hybrid similarity measure for case retrieval in $\mathrm{CBR}$ and its application to emergency response towards gas explosion.Expert Systems with Applications.41 (2014) 2526-2534. 